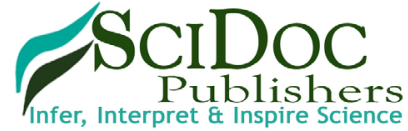

\section{Association between High Sensitive-C Reactive Protein and Lipid Cardiovascular Risk Factors in Apparently Healthy Nigerian Young Adults}

International Journal of Diabetology \& Vascular Disease Research (IJDVR) ISSN:2328-353X

Sonuga $\mathrm{O} \mathrm{O}^{1 *}$, Sonuga A A², Abbiyesuku FM ${ }^{1}$

${ }^{1}$ Department of Chemical Pathology, University College Hospital, PMB, Ibadan, Nigeria.

${ }^{2}$ Department of Science Laboratory Technology (Biochemistry Option), Ekiti State University, PMB, Ado-Ekiti, Nigeria.

\title{
Abstract
}

Background: CVD, in which coronary heart disease is the main manifestation, remains the major cause of morbidity and mortality worldwide. Chronic inflammatory process which starts from childhood tracking to adulthood has been reported to play a major role in the development and progression of atherogenesis leading to coronary heart disease. hs-CRP, an inflammatory marker has also been shown to best predict development of CVD even in the absence of traditional risk factors. Aim of this study is to ascertain hs-CRP as an independent risk factor as other lipid risk factors in young adults yet to develop CVD or other associated conditions.

Methods: 150 age-matched healthy young adults were recruited into this cross-sectional study. They were grouped into three based on the level of hs-CRP; (Group A <3.0mg/L, Group B 3.0-10.0mg/L and Group C>10.0mg/L). Anthropometric measurement, plasma Total cholesterol, Triglycerides, HDL-cholesterol, LDL-cholesterol, serum hs-CRP, Lipoprotein(a), Apolipoprotein A1, Apolipoprotein B and ApoB/A1 ratio were determined in the participants using standard methods.

Results: There is a significant rising trend in weight, body mass index and waist-hip ratio in proportion to the increasing level of hs-CRP ( $\mathrm{p}=0.021, \mathrm{p}=0.004$ and $\mathrm{p}=0.029$ respectively). The HDL-cholesterol and ApoA1 levels significantly reduce in proportion to the rising levels of hs-CRP ( $\mathrm{p}=0.000$ and $\mathrm{p}=0.028$ respectively). Also the total cholesterol correlates positively with hs-CRP $(r=0.182, p=0.026)$, while a negative correlation exists between hs-CRP and HDL-cholesterol $(r=-0.321, p=0.000)$ and ApoA1 ( $\mathrm{r}=-0.246, \mathrm{p}=0.002)$.

Conclusions: This study has demonstrated that increase in central or visceral adiposity, plasma total cholesterol, triglycerides, ApoB; and decreases in plasma HDL-cholesterol and ApoA1, can invoke vascular inflammation which can be detected early by rising concentration of hs-CRP even in young individuals yet to develop CVD.

Keywords: High-Sensitive C Reactive Protein; Lipid Cardiovascular Risk Factors; Vascular Inflammation; Healthy Young Adults.

\section{Introduction}

Atherosclerosis remains the major cause of death in developing and developed countries, regardless of the various differences in ethnicities, habits, cultures and availability of affordable therapies $[1]$.

It's a known fact that $50 \%$ of all myocardial infarctions occur among individuals without overt hyperlipidaemia, inspite of the strong association of lipid concentrations with coronary heart disease risk (CHD) [2]. It has been shown that about $20 \%$ of all coronary events occurred in the absence of any of the traditional risk factors, such as hypertension, diabetes mellitus, hyperlipidaemia and smoking [3]. These findings raise the query if these conventional risk factors are sufficient to recognize individuals at increased risk of CHD. Therefore various non-lipid atherogenic markers have been suggested in an effort to better determine individuals at risk of CHD, these include markers of inflammation (high sensitivity C-reactive protein, interleukins, adhesion molecules, heat shock proteins); markers of fibrinolytic and haemostatic function (D-dimers, fibrinogen, thrombinantithrombin III complex); homocysteine to mention but few. Of all these non-lipid risk markers available, high sensitivity C-reactive protein (hs-CRP) is considered to be the most robust tool with test uniqueness desirable and favorable for clinical use as novel marker for CHD risk [4].

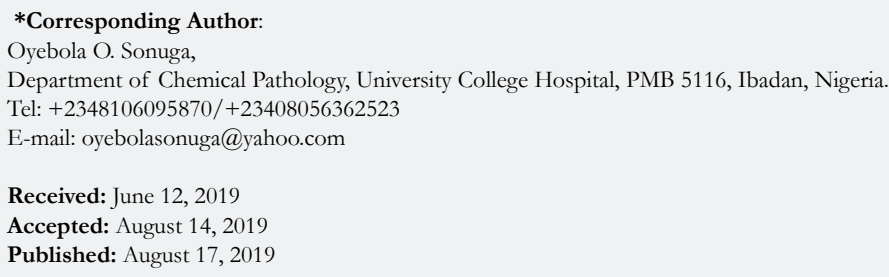

Copyright: Sonuga $\mathbf{O} \mathbf{O}^{\circ}$ 2019. This is an open-access article distributed under the terms of the Creative Commons Attribution License, which permits unrestricted use, distribution and reproduction in any medium, provided the original author and source are credited. 
C-reactive protein (CRP) is an acute phase reactant, produced in the liver and routinely measured as an indication of acute infections, inflammatory conditions and trauma; but for the purpose of CHD, it requires the use of hs-CRP assays that have adequate sensitivity to quantify CRP throughout its normal range [5].

CHD, a manifestation of atherosclerosis and chronic inflammatory condition that most often starts at a very young age [6], plays a critical role in the development and progression of atherosclerosis at all stages [7]. Several epidemiologic studies have also shown that elevated concentrations of hs-CRP, a marker for low grade inflammation are strongly associated with risk of future coronary events [8-10]. A number of prospective studies have consistently confirmed that a single hs-CRP measurement can independently predict vascular risk both in apparently healthy men and women that are asymptomatic for traditional risk factors of cardiovascular disease (CVD) [1, 10]; and also predict risk of future coronary events in patients with acute coronary syndromes [11]. hs-CRP has been found to be the strongest predictor of coronary events compared to other novel biochemical [12] and traditional markers of CHD risks [13]. Studies have shown that there is a strong association between hs-CRP and other conditions that confers CVD risks such as metabolic syndrome, impaired glucose tolerance, type 2 diabetes mellitus and hypertension [14$17]$.

Research findings have indicated that CRP enhances the expression of local endothelial cell surface adhesion molecules [18], endothelial plasminogen activator inhibitor-1 [19], endothelin-1 [20] and monocyte chemoattractant protein-1 [18]; increases the induction of monocyte tissue factors [21]; increases LDLCholesterol uptake by macrophages [20]; reduces endothelial nitric oxide bioactivity [22] and co-localize with the complement membrane attack complex within atherosclerotic lesion [23]. These findings suggest CRP as real contributor to atherogenesis apart from just a marker of inflammation [24].

The American Heart Association/Centre for Disease Control (AHA/CDC) Working Group on markers of inflammation in CVD has classified risk of developing CVD based on serum levels of hs-CRP, on account of data obtained from population studies. hs-CRP concentration of $<1 \mathrm{mg} / \mathrm{L}$ is classified as lowrisk; $1-3 \mathrm{mg} / \mathrm{L}$ as intermediate-risk; and levels $>3 \mathrm{mg} / \mathrm{L}$ as high-risk in developing CVD [25]. It is important to note that the association of hs-CRP with CVD risk may be confounded by racial/ethnic differences. Interestingly, marked racial/ethnic differences in hs-CRP levels have been reported, with individual of African origin having higher concentrations compared to Caucasians, independent of adiposity [26-28]; this might affect the interpretation of hs-CRP in risk prediction in African population. Given that chronic inflammatory process starts from childhood and tracks to adulthood; and that it plays a causative role in development and progression of atherosclerosis; and also in view of the fact that hs-CRP is both marker and aetiological factor in atherogenesis; it is important to evaluate the relationship between hs-CRP and CVD risk factors in apparently healthy young population so as to detect early the onset of atherogenesis, and to commence early intervention and preventive measures. We hypothesized that the higher the concentrations of circulating hs-CRP, the stronger its association with other markers of CVD risks, even in apparently healthy young population who are yet to develop CVDs.

\section{Methods}

\section{Study Participants}

This is a cross-sectional study carried out among 150 apparently healthy young adults' aged between 18 and 25 years from South West, Nigeria over a period of 6 months. A non-random sampling technique was used to select the study participants. They were grouped into three based on the serum level of hsCRP; group A (hsCRP: $\leq 3.0 \mathrm{mg} / \mathrm{L}$ ), group B (hsCRP: $3.0-10.0 \mathrm{mg} / \mathrm{L}$ ), and group C (hsCRP: $>10.0 \mathrm{mg} / \mathrm{L}$ ) according to a study on plasma distribution of hsCRP in healthy Nigerian adults [9]. The inclusion criteria is voluntary consent to participate, while the exclusion criteria included (a) history of chronic illness or chronic use of any form of medication especially steroid/lipid lowering drugs, (b) acute illness or any treatment of inflammatory or chronic infectious disease either before or at the time of the investigation (c) social habits such as smoking, alcohol consumption. The study was approved by the University of Ibadan/University College Hospital Ibadan Health Research Ethics Committee (No. UI/ EC/16/0301).

\section{Data Collection}

A questionnaire-based interview was used to collect information on demographic characteristics, clinical measurements, personal and family medical history of diabetes mellitus, hypertension and coronary events. Informed written consent form was obtained from all participants after educating them on the benefits and relevance of the study. Clinical measurements which included weight $(\mathrm{Kg})$, height (meters) were measured with participants in light clothing without shoes using a stadiometer and the stadiometer's head piece, respectively. Body Mass Index was calculated as Weight/ Height $^{2}\left(\mathrm{~kg} / \mathrm{m}^{2}\right)$. Waist circumference (centimeters) was measured using a non-stretch measuring tape at the midpoint between the lowest rib and the iliac crest in the horizontal plane. Hip circumference (centimeters) was measured horizontally at the level of the maximum extension of the buttocks. Waist-hip ratio (WHR) was calculated by the standard equation [WHR = Waist circumference $(\mathrm{cm}) /$ Hip circumference $(\mathrm{cm})]$. Blood pressure was measured twice (10 minutes apart), on the left arm of participants in a relaxed, sitting position with the arm supported at heart level, using a standard mercury sphygmomanometer. The mean of the two readings was calculated to obtain the final blood pressure. $10 \mathrm{mls}$ of venous blood specimen was withdrawn from each participant in the morning between 7.00am and 9.00am, after 1012 hours of overnight fast. $5 \mathrm{mls}$ was dispensed into EDTA bottle for fasting lipid profile (TC, TG, HDL-c, LDL-c) estimation and another $5 \mathrm{mls}$ into Gel clot activator bottle for estimation of serum hs-CRP and other lipid studies. Respective plasma and serum samples were analyzed within 3 months.

\section{Assay Methods}

Plasma Total cholesterol, HDL-c and TG were determined by enzymatic methods; cholesterol-oxidase, direct HDL PEGME, and lipase/glycerol phosphate-oxidase respectively, using G Cell laboratories reagents on an automated chemistry analyzer 
(LandWind C 100 plus). The Friedewald equation was used to calculate LDL-c [LDL-C $(\mathrm{mg} / \mathrm{dL})=$ Total Cholesterol- HDL-c -(TG/5)]. Serum ApoB andApoA1 were measured using immunoturbidimetric assays ( $\mathrm{G}$ Cell laboratories reagents) on an automated chemistry analyzer (LandWind C 100) plus). Serum hsCRP and Lp(a) levels were manually measured using enzyme linked immunosorbent assay (CALBIOTECH Diagnostics kits) on microplate reader (StatFax 4200, USA).

\section{Statistical Analysis}

The statistical analysis was performed using Statistical Package for Social Sciences version 20.0. Data were normally distributed, after checking for normality using the Kolmogorov-Smirnov test. All results are expressed as mean (SD). One-way ANOVA was used to compare group means for anthropometric data, clinical data and lipid studies across the three groups. Pearson's correlation analysis was carried out to determine the association of hsCRP with anthropometric data and lipid cardiovascular risk factors. The level of significance was taken to be $\mathrm{p}<0.05$.

\section{Results}

\section{Demographic Characteristics of the Study Population}

A total of 150 apparently healthy age-matched, young adults, were recruited for this study. They were grouped into three based on their serum hsCRP level. 50 participants are in group A (hsCRP: $\leq 3.0 \mathrm{mg} / \mathrm{L}$ ), 56 participants in group B (hsCRP: $3.0-10.0 \mathrm{mg} / \mathrm{L}$ ) and 44 participants in group C (hsCRP:>10mg/L).

\section{Comparison of Anthropometric and Clinical Data in the three groups}

The weight and BMI were significantly higher $(\mathrm{p}<0.05)$ in group $\mathrm{C}$ when compared to both groups A and B. Also the WHR was significantly higher $(\mathrm{p}<0.05)$ in group $\mathrm{C}$ when compared to group A. The height, waist circumference, hip circumference, systolic and diastolic blood pressure were not statistically different ( $>0.05)$ across the three groups. Table 1.

\section{Comparison of lipid cardiovascular risk factors in the three groups}

Total cholesterol was significantly higher in group C $(\mathrm{p}<0.05)$ when compared to group A. The HDL-C concentration was significantly lower in group $\mathrm{C}(\mathrm{p}<0.05)$ when compared to groups $\mathrm{A}$ and $\mathrm{B}$; while it is also significantly lower in group $\mathrm{B}(\mathrm{p}<0.05)$ compared to that of group A. Triglycerides was significantly higher $(\mathrm{p}<0.05)$ in group $\mathrm{C}$ compared to group $\mathrm{B}$; while $\mathrm{ApoB}$ and ApoB/ApoA1 ratio in group $\mathrm{C}$ were significantly higher $(\mathrm{p}<0.05)$ than those of group A. ApoA1concentration was significantly higher $(p<0.05)$ in group A when compared to group C. There was no significant difference $(\mathrm{p}>0.05)$ in LDL-c and Lp(a) across the groups. Table 2

\section{Correlation of hsCRP with anthropometric and clinical data}

There was no correlation between hsCRP, measured anthropometric and clinical data in this study. Table 3

\section{Correlation of hsCRP with lipid cardiovascular risk factors}

There was a positive correlation between hsCRP and Total cholesterol; and a negative correlation between hsCRP and HDL-c and ApoA1 in this study. Table 4

\section{Discussion}

hs-CRP, a marker of inflammation have been shown to predict the development of cardiovascular diseases (CVD) even in the absence of traditional risk factors. It is also more robust compared to other novel markers in predicting coronary events. This study therefore looked at the relationship of hs-CRP levels and some traditional risk factors in apparently healthy young adults of African descent. The participants are yet to develop CVD, type II diabetes mellitus, metabolic syndrome or any other chronic disease condition; these could explain the relatively "normal" values obtained in this study.

This present study showed that the measures of adiposity (BMI, WHR) rise significantly in proportion to the increasing levels of

Table 1. Comparison of Anthropometric and Clinical Data in the three groups.

\begin{tabular}{|c|c|c|c|c|}
\hline Parameters & $\begin{array}{c}\text { Group A (n=50) } \\
\text { (hsCRP } \leq \text { 3.0mg/L) } \\
\text { mean (SD) }\end{array}$ & $\begin{array}{c}\text { Group B (n=56) } \\
\text { (hsCRP 3.0-10mg/L) } \\
\text { mean (SD) }\end{array}$ & $\begin{array}{c}\text { Group C (n=44) } \\
\text { (hsCRP > 10mg/L) } \\
\text { mean (SD) }\end{array}$ & p value \\
\hline Height $(\mathrm{m})$ & $1.65(0.07)$ & $1.64(0.06)$ & $1.65(0.08)$ & 0.915 \\
\hline Weight $(\mathrm{Kg})$ & $56.4(10.2)$ & $57.5(7.87)$ & $61.0(8.15)^{\mathrm{a}, \mathrm{b}}$ & $0.021^{*}$ \\
\hline BMI $\left(\mathrm{Kg} / \mathrm{m}^{2}\right)$ & $20.7(2.77)$ & $21.4(2.53)$ & $22.4(2.56)^{\mathrm{a}, \mathrm{b}}$ & $0.004^{*}$ \\
\hline WC $(\mathrm{cm})$ & $75.1(5.91)$ & $75.2(6.87)$ & $77.9(8.57)$ & 0.094 \\
\hline HC $(\mathrm{cm})$ & $93.8(5.05)$ & $93.3(7.86)$ & $94.6(7.87)$ & 0.626 \\
\hline WHR & $0.80(0.06)$ & $0.81(0.04)$ & $0.82(0.04)^{\mathrm{a}}$ & $0.029^{*}$ \\
\hline SBP $(\mathrm{mmHg})$ & $110(10.65)$ & $112(16.42)$ & $114(11.75)$ & 0.239 \\
\hline DBP $(\mathrm{mmHg})$ & $72(10.26)$ & $72(10.66)$ & $74(8.09)$ & 0.825 \\
\hline
\end{tabular}

$\left({ }^{*} \mathrm{p}<0.050\right.$; asignificantly different from group A; bsignificantly different from group B; csignificantly different from group C). BMIBody Mass Index; WC- Waist Circumference; HC- Hip Circumference; WHR- Waist Hip Ratio; SBP- Systolic Blood Pressure; DBPDiastolic Blood Pressure 
Table 2. Comparison of lipid cardiovascular risk factors in the three groups.

\begin{tabular}{|c|c|c|c|c|}
\hline Parameters & $\begin{array}{c}\text { Group A (n=50) } \\
\text { (hsCRP } \mathbf{3 . 0 m g / L )} \\
\text { mean (SD) }\end{array}$ & $\begin{array}{c}\text { Group B (n=56) } \\
\text { (hsCRP 3.0-10mg/L) } \\
\text { mean (SD) }\end{array}$ & $\begin{array}{c}\text { Group C (n=44) } \\
\text { (hsCRP > 10mg/L) } \\
\text { mean (SD) }\end{array}$ & p value \\
\hline Height $(\mathrm{m})$ & $152(22.13)$ & $155(27.50)$ & $164(30.98)^{\mathrm{a}}$ & 0.093 \\
\hline Weight $(\mathrm{Kg})$ & $64(11.48)^{\mathrm{b}, \mathrm{c}}$ & $60(9.23)^{\mathrm{c}}$ & $53(10.91)$ & $0.000^{*}$ \\
\hline BMI $\left(\mathrm{Kg} / \mathrm{m}^{2}\right)$ & $68(20.64)$ & $67(16.98)$ & $75(21.28)^{\mathrm{b}}$ & 0.088 \\
\hline WC (cm) & $74(25.41)$ & $82(25.83)$ & $96(29.62)$ & 0.635 \\
\hline HC $(\mathrm{cm})$ & $69(22.71)$ & $73(18.88)$ & $74(18.18)$ & 0.392 \\
\hline WHR & $80(22.92)$ & $87(19.17$ & $89(23.37)^{\mathrm{a}}$ & 0.08 \\
\hline SBP $(\mathrm{mmHg})$ & $173(21.22)^{\mathrm{c}}$ & $169(12.49)$ & $163(17.99)$ & 0.028 \\
\hline DBP $(\mathrm{mmHg})$ & $0.46(0.14)$ & $0.51(0.19)$ & $0.55(0.16)^{\mathrm{a}}$ & 0 \\
\hline
\end{tabular}

$\left({ }^{*} \mathrm{p}<0.050\right.$; asignificantly different from group A; bsignificantly different from group B; c significantly different from group C). TCTotal cholesterol; HDL- High density lipoprotein cholesterol; TG- Triglycerides; LDL- Low density cholesterol; Lp(a)- Lipoprotein (a); ApoB-Apolipoprotein B; ApoA1-Apolipoprotein A1.

Table 3. Correlation of hsCRP with anthropometric and clinical data.

\begin{tabular}{|c|c|c|}
\hline \multirow{2}{*}{$\begin{array}{c}\text { Anthropometric } \\
\text { Clinica1 data }\end{array}$} & \multicolumn{2}{|c|}{ hsCRP } \\
\cline { 2 - 3 } $\mathbf{r}$ & $\mathbf{p}$ \\
\hline Height $(\mathrm{m})$ & 0.073 & 0373 \\
\hline Weight $(\mathrm{Kg})$ & 0.027 & 0.745 \\
\hline BIVII $\left(\mathrm{Kg} / \mathrm{m}^{2}\right)$ & 0.008 & 0.927 \\
\hline WC $(\mathrm{cm})$ & 0.097 & 0.235 \\
\hline HC $(\mathrm{cm})$ & 0.044 & 0.596 \\
\hline WHR & 0.122 & 0.135 \\
\hline SBP $(\mathrm{mmHg})$ & 0.056 & 0.494 \\
\hline DBP $(\mathrm{mmHg})$ & 0.027 & 0.744 \\
\hline \multicolumn{2}{|c}{$\left(* \mathrm{p}<0 \_050\right)$} \\
\hline
\end{tabular}

BMI- Body Mass Index; WC- Waist Circumference; HC- Hip Circumference; WHR- Waist Hip Ratio; SBP- Systolic Blood Pressure; DBP- Diastolic Blood Pressure

Table 4. Correlation of hsCRP with lipid cardiovascular risk factors.

\begin{tabular}{|c|c|c|}
\hline \multirow{2}{*}{ CVD Parameters } & \multicolumn{2}{|c|}{ hsCRP } \\
\cline { 2 - 3 } & $\mathbf{r}$ & $\mathbf{p}$ \\
\hline TC $(\mathrm{mg} / \mathrm{dL})$ & 0.182 & $0.026^{*}$ \\
\hline HDL $(\mathrm{mg} / \mathrm{dL})$ & -0.321 & $0.000^{*}$ \\
\hline TG $(\mathrm{mg} / \mathrm{dL})$ & 0.138 & 0.092 \\
\hline LDL $(\mathrm{mg} / \mathrm{dL})$ & 0.071 & 0.386 \\
\hline Lp (a) (mg/dL) & -0.008 & 0.920 \\
\hline Apo B (mg/dL) & 0.040 & 0.630 \\
\hline Apo A1 (mg/dL) & -0.246 & $0.002 *$ \\
\hline ApoB/ApoA1 & 0.138 & 0.092 \\
\hline \multicolumn{2}{|c|}{$\left({ }^{*} \mathrm{p}<0 \_050\right)$} \\
\hline
\end{tabular}

TC-Total cholesterol; HDL- High density lipoprotein cholesterol; TG- Triglycerides; LDL- Low density cholesterol; Lp(a)- Lipoprotein (a); ApoB-Apolipoprotein B; ApoA1-Apolipoprotein A1. 
hs-CRP, this is similar to the findings of [29, 30]. Finding of this study supports the body of evidence that adipose tissue is a major source of cytokines and that increased body fat is a state of low grade systemic inflammation; therefore we propose that hs-CRP production rises with increasing visceral or central adiposity which can lead to the development of CVD, even when an individual is not overweight or obese.

This study also showed a significant rising trend in total cholesterol and triglycerides with increasing tertile level of hs-CRP; this finding correlates with the reports of $[31,32]$. It is known that triglyceride rich lipoproteins such as VLDL and chylomicron contain significant amount of cholesterol and infiltration of these TG rich lipoproteins in the arterial wall sub-endothelial space is a critical event that sparks an inflammatory response, promoting the development of atherosclerosis. Therefore it can be deduced from this study that even when total cholesterol and TG are within normal limits, there increasing level potentiates inflammatory response as shown by increased hs-CRP.

HDL-cholesterol is a key factor in the reverse cholesterol transport pathway and has many valuable properties, including anti-inflammatory, anti-oxidative, anti-thrombotic, anti-infectious, anti-apoptotic, intercellular communication, and pro-vasodilatory capacities. It has been clearly established in numerous epidemiological studies that an inverse relationship exists between HDL-C levels and risk of CVD. It is observed in this present study that HDL-cholesterol levels decrease as hs-CRP levels rise in agreement with the reports by [33, 34]. Rafael et al., [33] reported that "a decrease of $1 \mathrm{mg} / \mathrm{dL}(0.0259 \mathrm{mmol} / \mathrm{L})$ in HDL cholesterol level increased the expected level of CRP by $14.6 \%$ ". It can be deduced therefore from this present study that the lower the HDL-cholesterol the higher the likelihood of inflammation, enhancing the development of CVD.

Studies have identified that Apo B, which represents total atherogenic particles plays a role in vascular inflammation and is a better predictor of CVD than LDL-C and non-HDL-C [35-37]. Reports have also shown that Apo A1, the major apolipoprotein in HDL-cholesterol particles has been identified as a better risk predictor than HDL cholesterol and it is considered as an antiatherogenic marker $[38,39]$. The ApoB/ApoA1 ratio reflects the balance between the opposing processes of arterial internalization of cholesterol and the reverse transport of cholesterol back to the liver [40]; such that the higher the value of the ApoB/ ApoA-1 ratio, the more cholesterol is likely to be deposited in the arterial wall, thereby provoking atherogenesis and hence also increasing cardiovascular risk [41]. This study revealed that ApoB concentration and $\mathrm{ApoB} / \mathrm{ApoA} 1$ ratio increase across the increasing levels of hs-CRP while ApoA1 concentration decreases; this pattern is also observed with triglycerides and HDL-cholesterol above. This discovery is similar to the findings of Wanhua et al in 2012 [42] and we can construe from this present study that elevated levels of $A p o B$ or $A p o B / A p o A 1$ ratio and lower concentration of ApoA1 can trigger vascular inflammation resulting in increased level of hs-CRP even when an individual is yet to develop CVD.

In this present study, hs-CRP negatively correlates with HDLcholesterol and ApoA1; and positively correlates with total cholesterol comparable to the report by Aleksandra et al, Debdutta et al and Wanhua et al., [31, 34, 42]. This observation supports the anti-inflammatory role of HDL-C and ApoA1; and the atherogenecity associated with increase cholesterol.

\section{Conclusion}

The observations from this study indicate that increase in central or visceral adiposity; increase in total cholesterol, triglycerides and ApoB; and decrease in HDL-cholesterol and ApoA1, can invoke vascular inflammation which can be detected early by increasing concentration of hs-CRP even in individual without overt CVD. Therefore we propose that in the absence of other inflammatory conditions, individuals especially at risk of CVD should have routine monitoring of their hs-CRP levels. Weight reduction and ensuring optimal lipid profile can help in preventing chronic inflammation and protecting against atherogenesis.

\section{Study Limitations}

Leukocyte count and erythrocyte sedimentation rate (ESR) were not done in this study.

\section{References}

[1]. Fonseca FA, Izar MC. High-Sensitivity C - reactive protein and Cardiovascular Disease across Countries and Ethnicities. Clinics (Sao Paulo). 2016 Apr;71(4):235-42. PubMed PMID: 27166776.

[2]. Remaley AT, Rifai N, Warnick GR. Lipids, Lipoproteins, Apolipoproteins, and other cardiovascular risk factors. In: Carl AB, Edward RA, David EB, eds. Tietz Textbook of Clinical Chemistry and Molecular Diagnostics. 5th ed. Missouri, Elsevier-Saunders; 2012: 731-805.

[3]. Nelson RH. Hyperlipidemia as a Risk Factor for Cardiovascular Disease. Prim Care. 2013 Mar; 40(1): 195-211.

[4]. Davis FJ, Vidyasagar S, Maiya GA. C-reactive protein and coronary heart disease-risk marker or risk factor. J Clin Sci Res. 2012 Oct 1;1:178-86.

[5]. Ridker PM. A Test in Context: High-Sensitivity C-Reactive Protein. J Am Coll Cardiol. 2016 Feb 16;67(6):712-723. PubMed PMID: 26868696.

[6]. Zhao XQ Seimon TA, Nadolski MJ, Lia X. Pathogenesis of Atherosclerosis. UptoDate. 2018.

[7]. Zhu Y, Xian X, Wang Z, Bi Y, Chen Q, Han X, et al., Research Progress on the Relationship between Atherosclerosis and Inflammation. Biomolecules. 2018 Sep; 8(3): 80.

[8]. Rodríguez-Hernández H, Simental-Mendía LE, Rodríguez-Ramírez G, Reyes-Romero MA. Obesity and Inflammation: Epidemiology, Risk Factors, and Markers of Inflammation. Int J Int J Endocrinol. 2013; 2013: 678159.

[9]. Yahaya IA. Distribution of plasma C-reactive protein measured by highsensitivity assay in healthy Nigerian adults. Sub-Saharan African Journal of Medicine. 2014 Jan 1;1(1):26-30.

[10]. Shrivastava AK, Singh HV, Raizada A, Singh SK. C-reactive protein, inflammation and coronary heart disease. The Egyptian Heart Journal. 2015 Jun $1 ; 67(2): 89-97$.

[11]. Milano SS, Moura Júnior OV, Bordin AA, Marques GL. C-reactive Protein is a Predictor of Mortality in ST-segment Elevation Acute Myocardial Infarction. International Journal of Cardiovascular Sciences. 2019 Apr;32(2):118-24.

[12]. Cacko A, Kondracka A, Gawałko M, Główczyńska R, Filipiak KJ, Bartoszewicz Z, et al. Novel biochemical predictors of unfavorable prognosis for stable coronary disease. Medicine (Baltimore). 2018 Sep; 97(37): e12372.

[13]. Tong DC, Whitbourn R, MacIsaac A, Wilson A, Burns A, Palmer S, et al., High-Sensitivity C-Reactive Protein Is a Predictor of Coronary Microvascular Dysfunction in Patients with Ischemic Heart Disease. Front Cardiovasc Med. 2017; 4: 81 .

[14]. Najafipour M, Khalaj MR, Zareizadeh M, Najafipour F. Relationship between high-sensitivity C-reactive protein and components of metabolic syndrome. J Res Med Dent Sci. 2018 May 1;6:7-11.

[15]. Babu LE, Joshi A. Correlation of high-sensitivity C-reactive protein with blood sugar level in patients with Type 2 diabetes. National Journal of Physiology, Pharmacy and Pharmacology. 2018;8(1):37-41.

[16]. Effoe VS, Correa A, Chen H, Lacy ME, Bertoni AG. High-Sensitivity C-Reactive Protein Is Associated With Incident Type 2 Diabetes Among African Americans: The Jackson Heart Study. Diabetes Care. 2015 Sep;38(9):1694- 
700. PubMed PMID: 26068864

[17]. Sinha S, Kar K, Soren M, Dasgupta A. hsCRP in pre-hypertension and hypertension: a prospective study in Southern Asian region. Int J Res Med Sci. 2017;2(4):1402-7

[18]. Pasceri V, Cheng JS, et al., Modulation of C-reactive protein-mediated monocyte chemoattractant protein-1 induction in human endothelial cells by anti-atherosclerosis drugs. Circulation. 2001 May 29;103(21):2531-4. PubMed PMID: 11382718.

[19]. Devaraj S, Xu DY, Jialal I. C-reactive protein increases plasminogen activator inhibitor-1 expression and activity in human aortic endothelial cells; implications for the metabolic syndrome and atherothrombosis. Circulation. 2003 Jan 28;107(3):398-404.

[20]. Verma S1, Li SH, Badiwala MV, Weisel RD, Fedak PW, Li RK, et al., Endothelin antagonism and interleukin-6 inhibition attenuate the proatherogenic effects of C-reactive protein. Circulation. 2002 Apr 23;105(16):18906. PubMed PMID: 11997273.

[21]. Nakagomi A, Freedman SB, et al., Interferon-gamma and lipopolysaccharide potentiate monocyte tissue factor induction by $\mathrm{C}$-reactive protein: relationship with age, sex, and hormone replacement treatment. Circulation. 2000 Apr 18;101(15):1785-91. PubMed PMID: 10769278.

[22]. Zwaka TP, Hombach V, et al. C-reactive protein mediated low density lipoprotein uptake by macrophages: implications for atherosclerosis. Circulation. 2001 Mar 6;103(9):1194-7. PubMed PMID: 11238260.

[23]. Torzewski J, Torzewski M, et al. C-reactive protein frequntly colocalizes with the terminal complement in the intima of early atherosclerotic lesions of human coronary arteries. Arterioscler Thromb Vasc Biol. 1998 Sep;18(9):1386-92. PubMed PMID: 9743226.

[24]. Badimon L, Peńa E, Arderiu G, Padró T, Slevin M, Vilahur G et al. CReactive Protein in Atherothrombosis and Angiogenesis. Front Immunol. 2018; 9: 430 .

[25]. Pearson TA, Mensah GA, Alexander RW, Anderson JL, Cannon III RO, Criqui $\mathrm{M}$, et al. Markers of inflammation and cardiovascular disease: application to clinical and public health practice: a statement for healthcare professionals from the Centers for Disease Control and Prevention and the American Heart Association. circulation. 2003 Jan 28;107(3):499-511.

[26]. Khan UI, Wang D, Sowers MR, Mancuso P, Everson-Rose SA, Scherer PE, et al. Race-ethnic differences in adipokine levels: the study of Women's health across the nation (SWAN). Metabolism. 2012 Sep;61(9):1261-9. PubMed PMID: 22444780.

[27]. Morimoto Y, Conroy SM, Ollberding NJ, Kim Y, Lim U, Cooney RV, et al. Ethnic differences in serum adipokine and C-reactive protein levels: the multiethnic cohort. Int J Obes (Lond). 2014 Nov;38(11):1416-22. PubMed PMID: 24522245.

[28]. Mokhaneli MC, Fourie CM, Botha S, Mels CM. The association of oxidative stress with arterial compliance and vascular resistance in a bi-ethnic population: the SABPA study. Free Radic Res. 2016 Aug;50(8):920-8. PubMed PMID: 27297811

[29]. Ding D, Min W, Dongfang S, Changjiang H, Xinrui L, Yunou Y, et al. Body Mass Index, High-Sensitivity C-Reactive Protein and Mortality in Chinese with Coronary Artery Disease. 2015. PLoS One. 2015 Aug 17;10(8):e0135713. PubMed PMID: 26280165. doi:10.1371/journal. pone. 0135713

[30]. Farooq SN, Ahmed A, Mustufa MA, Rizvi MI. High Sensitivity C-Reactive Protein Level Increases with Rise in Body Mass Index and not Affected by Perceived Stress in Young Saudis. Annals of Medical and Health Sciences Research. 2017;7(4):224-229.

[31]. Aleksandra NK, Nadja DV, Tatjana PS, Tatjana ID, Milos ZM, Marija GM. Association Between C-Reactive Protein, Anthropometric and Lipid Parameters Among Healthy Normal Weight and Overweight Postmenopausal Women in Montenegro. Lab Med. 2014 Winter;45(1):12-6. PubMed PMID: 24719979.

[32]. Kyoko O, Norihiro F, Masayuki M, Yasunori S, Mosaburo K, Jun H. A hypertriglyceridemic state increases high sensitivity C-reactive protein of Japanese men with normal glucose tolerance. Endocrine. 2012 Feb;41(1):96102. PubMed PMID: 21948178.

[33]. Rafael ABN, Fernando A, Gustavo FC, Gisela TS, Alfredo J M. Highsensitivity C-reactive protein levels and treadmill exercise test responses in men and women without overt heart disease. Exp Clin Cardiol. 2013 Spring;18(2):124-8. PubMed PMID: 23940437.

[34]. Debdutta G, Nilanjan D, Indranil S, Krishna RS, Debnath C, Saurabh $\mathrm{G}$, et al. Association between Inflammatory Markers and Cardiovascular Risk Factors in Women from Kolkata, W.B, India. Arq Bras Cardiol. 2011 Jan;96(1):38-46. PubMed PMID: 21180893.

[35]. Vaverkova H. LDL-C or apoB as the best target for reducingcoronary heart disease: should apoB be implemented into clinical practice?. Clinical Lipidology. 2011 Feb 1;6(1):35-48.

[36]. Upadhyay RK. Emerging Risk Biomarkers in Cardiovascular Diseases and Disorders. J Lipids. 2015;2015:971453: 1-50. PubMed PMID: 25949827. http://dx.doi.org/10.1155/2015/971453.

[37]. D’Adamo E, Guardamagna O, Chiarelli F, Bartuli A, Liccardo D, Ferrari F et al. Atherogenic Dyslipidemia and Cardiovascular Risk Factors in Obese Children. Int J Endocrinol. 2015;2015:912047. 1-9. PubMed PMID: 25663838. http://dx.doi.org/10.1155/2015/912047.

[38]. Walldius G, Jungner I. Apolipoprotein A-I versus HDL cholesterol in the prediction of risk for myocardial infarction and stroke. Curr Opin Cardiol. 2007 Jul;22(4):359-67. PubMed PMID: 17556890. https://www.ncbi.nlm. nih.gov/pubmed/17556890

[39]. Rahim S, Abdullah HA, Ali Y, Khan UI, Ullah W, Shahzad MA, et al. Serum Apo A-1 and Its Role as a Biomarker of Coronary Artery Disease. Cureus. 2016 Dec; 8(12): e941.

[40]. Lu M, Lu Q, Zhang Y, Tian G. ApoB/apoA1 is an effective predictor of coronary heart disease risk in overweight and obesity. J Biomed Res. 2011 Jul; 25(4): 266-273.

[41]. Kaneva AM, Potolitsyna NN, Bojko ER, Odlan JO. The Apolipoprotein B/Apolipoprotein A-I Ratio as a Potential Marker of Plasma Atherogenicity. Dis Markers. 2015;2015:591454. PubMed PMID: 25852220. http:// dx.doi.org/10.1155/2015/591454.

[42]. Wanhua X, Rong L, Suhua Z, Lilin G, Zhihong W, Wei R, et al. The relationship between high-sensitivity C-reactive protein and ApoB, ApoB/ApoA1 ratio in general population of China. Endocrine. 2012 Aug;42(1):132-8. 